\title{
The Implementation of Javanese Local Wisdom Values as Strengthening the Practice of Pancasila
}

\author{
Bambang Sumardjoko', Arif Subowo²
}

Program Studi Pendidikan Pancasila dan Kewarganegaraan, Universitas Muhammadiyah Surakarta ${ }^{1}$, Program Studi Magister Pendidikan Pancasila dan Kewarganegaraan, Universitas Sebelas Maret Surakarta ${ }^{2}$

bs131@ums.ac.id ${ }^{1}$, arifsubowo50@gmail.com²

\section{Article History}

accepted 23/03/2021

approved 10/04/2021

published $20 / 04 / 2021$

\begin{abstract}
For the Indonesian people, Pancasila is the basis of the state and way of life, as well as the state ideology. In practice, it appears that the practice of Pancasila values is still weak and concerning. If this phenomenon is not handled seriously, it can become a threat to the existence of Pancasila in society, nation, and state. Indonesia is a country whose society is multicultural, consisting of various religions, races, tribes, cultures, and ethnicities, but has noble values that have been passed down from our ancestors to be preserved, namely Pancasila which unites the Indonesian nation. The Indonesian state consists of regions that have different local wisdom values. These values become guidelines and are cared for by all elements of society because they provide convenience in realizing national values. Even though each region has different local wisdom values, the Indonesian people remain united, namely 'Bhineka Tunggal Ika'. There are many Javanese local wisdoms and for people who uphold the values of Javanese local wisdom, consciously or unconsciously, they have contributed significantly to the practice of Pancasila. The writing of this article is intended to describe the implementation of Javanese local wisdom values as a form of strengthening the practice of Pancasila. The main issues raised include the values of Javanese local wisdom, the practice of Pancasila values, and the implementation of Javanese local wisdom values as a form of strengthening the experience of Pancasila values. Materials and methods of writing articles use library research which is sourced from primary and secondary data, namely from expert informants, books, and relevant research journals. Finally, in this paper it is stated that the implementation of Javanese local wisdom values will be able to strengthen the practice of Pancasila values in the midst of a multicultural Indonesian society.
\end{abstract}

Keywords: local wisdom values, Javanese society, and Pancasila

\section{Abstrak}

Bagi bangsa Indonesia Pancasila merupakan dasar negara dan pandangan hidup, sekaligus sebagai ideologi negara. Pada praktiknya saat ini tampak bahwa pengamalan nilai-nilai Pancasila tergolong masih lemah dan memprihatinkan. Fenomena ini jika tidak ditangani secara serius maka dapat menjadi ancaman bagi eksistensi Pancasila di tengah masyarakat, bangsa, dan negara. Indonesia adalah negara yang masyarakatnya multikultural, terdiri dari berbagai agama, ras, suku, budaya, dan etnik, tetapi mempunyai nilai-nilai luhur yang diwariskan nenek moyang untuk dilestarikan, yaitu Pancasila yang mempersatukan bangsa Indonesia. Negara Indonesia terdiri dari daerah-daerah yang mempunyai nilai-nilai kearifan lokal berbeda. Nilai-nilai itu menjadi pedoman dan dirawat oleh seluruh elemen masyarakat karena memberikan kemudahan dalam mewujudkan nilai-nilai Nasional. Meski setiap daerah memiliki nilai-nilai kearifan lokal berbeda, masyarakat Indonesia tetap bersatu yakni bhineka tunggal ika. Kearifan lokal Jawa banyak jumlahnya dan bagi masyarakat yang menjunjung tinggi nilai-nilai kearifan lokal Jawa secara sadar ataupun tidak disadari telah berkontribusi nyata bagi pengamalan Pancasila. Penulisan artikel ini dimaksudkan untuk mendeskripsikan implementasi nilai-nilai kearifan lokal Jawa sebagai bentuk penguatan pengamalan Pancasila. Pokok permasalahan yang dikemukakan meliputi nilai-nilai kearifan lokal Jawa, pengamalan nilai-nilai Pancasila, dan implementasi nilai-nilai kearifan lokal Jawa sebagai bentuk penguatan pengamalam nilai-nilai Pancasila. Bahan dan metode penulisan artikel menggunakan studi kepustakaan (library research) yang bersumber pada data primer dan skunder, yaitu dari informan ahli, buku, dan jurnal penelitian yang relevan. Akhirnya dalam penulisan ini dinyatakan bahwa dengan implementasi nilai-nilai kearifan lokal Jawa akan dapat menguatkan pengamalan nilai-nilai Pancasila di tengah masyarakat Indonesia yang multikultur.

Kata Kunci: nilai kearifan lokal, masyarakat Jawa, dan Pancasila

Social, Humanities, and Education Studies (SHEs): Conference Series p-ISSN 2620-9284 https://jurnal.uns.ac.id/shes 


\section{PENDAHULUAN}

Indonesia sebagai negara multikultural terbesar di dunia menjadi kekhasan yang terus dijaga dan dibanggakan (Nugraha, 2020). Indonesia memiliki wilayah yang luas, terdiri dari ribuan pulau yang di dalamnya terdapat suku, agama, ras, budaya, dan etnik yang berbeda. Setiap daerah memiliki budaya masing-masing dan menunjukkan kemajemukan budaya di Indonesia. Nilai-nilai budaya setiap daerah menunjukkan sebuah identitas daerah. Identitas tersebut merupakan simbol dan menjadi acuan dalam menjalani kehidupan bermasyarakat, berbangsa dan bernegara. Perbedaan yang terdapat di masyarakat Indonesia merupakan wujud sebuah kebhinekaan yang dijaga dan dilestarikan.

Kebudayaan Indonesia merupakan keseluruhan budaya yang terdapat di daerah, yang memiliki keragaman dan perbedaan budaya antara satu daerah dengan lainnya. Budaya Indonesia sudah dikenal di mancanegara sehingga banyak orang asing yang berkunjung ke Indonesia untuk mengenal lebih mendalam mengenai budaya Indonesia. Keragaman budaya yang dimiliki bangsa Indonesia sangat majemuk, meliputi kesenian, rumah adat, bahasa daerah, dan sebagainya, serta menjadi asset bangsa Indonesia yang harus dijaga dan dilestarikan agar keaslian dan eksistensinya tidak terkikis oleh perkembangan zaman yang begitu pesat.

Kemajemukan masyarakat di Indonesia ditunjukkan oleh adanya kekayaan budaya yang ada di berbagai daerah, yang dalam jejak sejarah memiliki beberapa suku, budaya, ras, etnik dan sebagainya. Salah satu daerah di Indonesia yang memiliki beragam budaya ialah Jawa. Pada masyarakat Jawa selain memiliki beberapa budaya adi luhung tinggi juga dikenal dari segi identitas masyarakatnya, yaitu memiliki perilaku sopan santun yang kuat, gigih dalam berusaha, tekun, dan pekerja keras (Nakrowi \& Pujiyanti, 2019).

Masyarakat yang masih memelihara budaya atau tradisi disebut kearifan lokal (local wisdom). Masyarakat ini mempertahankan budaya atau nilai-nilai tradisi di tengah kemajuan zaman, dan hal ini tidak dianggap sebagai masyarakat kuno atau terbelakang. Kearifan lokal bersumber dari kebudayaan masyarakat dalam suatu wilayah. Kearifan lokal adalah filosofi dan pandangan hidup yang terwujud di berbagai bidang kehidupan sosial, ekonomi, kesehatan, lingkungan dan sebagainya (Romadi dan Kurniawan dalam Octavia \& Nurlatifah, 2020). Kearifan lokal merupakan keseluruhan pengalaman, gagasan, pandangan hidup, nilai, norma, bahasa serta adat masyarakat yang dianggap baik untuk digunakan secara tradisional dari satu generasi ke generasi penerus bangsa di tanah air (Prasasti, 2020). Nilai-nilai kearifan lokal yang dimiliki oleh suku Jawa dapat menjadi sebuah acuan bagi masyarakat Jawa di dalam menjalani kehidupan yang sesuai dengan nilai-nilai Pancasila.

Pancasila merupakan dasar negara, pandangan hidup, dan ideologi bangsa, pada hakikatnya dirumuskan dari nilai adat-istiadat, kebudayaan, dan religius yang ada dalam berbagai pandangan masyarakat Indonesia sebelum dibentuk menjadi suatu negara. Nilai kebudayaan dan religius yang sudah ada di Indonesia dijadikan dasar dalam merumuskan Pancasila sebagai pandangan hidup bangsa, hal itu suatu komitmen untuk tetap satu sikap dan pandangan dalam mewujudkan tujuan nasional. Nilai-nilai yang terkandung dalam sila-sila Pancasila merupakan hasil kesepakatan para pendiri bangsa (founding fathers). Hasil kesepakatan yang terkandung dalam nilai-nilai Pancasila dijalankan dan diimplementasikan oleh seluruh rakyat Indonesia dalam kehidupan sehari-hari sehingga nilai-nilai Pancasila makin dirasakan manfaatnya. Namun pada realitanya masyarakat Indonesia belum melaksanakan atau mengamalkan nilai-nilai Pancasila secara utuh. Hal ini ditunjukkan masih adanya sikap dan perilaku masyarakat yang memprihatinkan dan bertentangan dengan nilai yang terkandung dalam Pancasila. Sebagai contoh adalah bahwa pada tahun 2020 terdapat oknum pejabat negara yang melakukan tindak korupsi (Menteri Sosial dan Kelautan) yang terjaring OTT (Operasi Tangkap Tangan) oleh KPK, saat pesta demokrasi tahun 
2019 (saat pemilihan Presiden dan Wakil Presiden) tahapan pemilu dapat dilaksanakan dengan baik tetapi terjadi peristiwa kurusuhan hingga menelan korban jiwa di Jakarta, berikutnya OPM (Organisasi Papua Merdeka) yang terus bergerak dan ingin memisahkan diri dari Indonesia. Pada skala lokal, di kota Surakarta pada tahun 2019 pernah terjadi peristiwa 'trabak lari' (di Manahan) yang menelan korban jiwa yang sampai saat ini pelaku penabrakan belum tertangkap meski telah terekam CCTV, dan tentu kejadian lain masih banyak yang dapat dikategorikan merupakan bentuk penerapan Pancasila yang masih memprihatinkan.

Mencermati berbagai fenomena atau kejadian di tengah masyarakat sebagaimana di atas maka menjadi hal penting untuk selalu mencari jalan keluar agar pengamalan nilai-nilai Pancasila di masyarakat makin kuat dan tetap eksis di tengah gempuran nilai budaya asing yang masuk ke tanah air Indonesia. Tujuan penulisan ini dimaksudkan untuk mendeskripsikan tentang (1) nilai-nilai kearifan lokal Jawa, (2) pengamalan nilai-nilai Pancasila, dan (3) implementasi nilai-nilai kearifan lokal sebagai bentuk penguatan pengamalan nilai-nilai Pancasila

\section{METODE}

Penulisan ini mendasarkan pada studi studi kepustakaan (Library Research) yaitu penulisan yang sumber data primer dan skundernya diperoleh dari buku-buku, jurnal penelitian, dan artikel yang berkaitan dengan rumusan masalah. Studi kepustakaan merupakan studi yang digunakan untuk mengumpulkan informasi, dengan bantuan berbagai macam material yang ada di perpustakaan seperti buku, dokumen, majalah, dan sebagainya (Mardalis dalam Mirzaqon and Purwoko, 2018). Studi kepustakaan merupakan teknik pengumpulan data dengan melakukan penelaahan terhadap buku, literatur, catatan, dan berbagai laporan yang relevan dengan masalah yang akan dipecahkan (Nazir dalam Kasari 2020) dan (Zer dalam Yeni and Hartati, 2020). Data yang diperoleh dari berbagai sumber dipergunakan untuk memperkuat landasan teori dan memecahkan permasalahan. Objek pada penulisan ini adalah implementasi nilai-nilai kearifan lokal Jawa sebagai bentuk penguatan pengamalan nilai-nilai Pancasila. Adapun yang menjadi subjek pembahasan adalah masyarakat Jawa.

\section{Nilai-nilai Kearifan Lokal Jawa}

\section{HASIL DAN PEMBAHASAN}

Kearifan lokal secara epistimologi terdiri dari dua kata, yaitu kearifan (wisdom) berarti kebijaksanaan sedangkan lokal (local) memiki arti setempat. Local wisdom dipahami sebagai gagasan, nilai, dan pandangan yang bersifat bijaksana yang dianggap baik oleh masyarakat. Kearifan lokal merupakan gagasan lokal yang bersifat bijaksana, penuh dengan kearifan, memiliki nilai yang tertanam dan diikuti oleh warga masyarakat setempat (Rumilah et al., 2021). Kearifan lokal merupakan kebijaksanaan atau pengetahuan asli suatu masyasakat yang berasal dari nilai leluhur tradisi budaya untuk mengatur kehidupan masyarakat.

Beberapa nilai kearifan lokal Jawa yang tampak di masyarakat luas, di antaranya adalah 'tepa slira' (toleransi), 'mawas diri', 'budi luhur' (budi pekerti), 'rukun' (cinta damai), 'rumangsa melu handarbeni' (peduli sosial), 'memayu hayuning bawana' (peduli lingkungan) dan 'aja dumeh' (menghargai, jujur, dan rendah hati). Suku Jawa memiliki beberapa kearifan lokal yang merupakan warisan dari nenek moyang sehingga menjadi sebuah tuntunan yang harus dijalankan oleh seluruh elemen masyarakat Jawa. Kebudayaan Jawa sebagai subkultul kebudayaan nasional Indonesia sudah mengakar bertahun-tahun menjadi pedoman dan pandangan hidup orang Jawa. Masyarakat Jawa memiliki identitas dan kepribadian yang menonjol atas dasar dari nasehat-nasehat nenek moyang yang turun-temurun dan menghormati kepada sesama. Berbagai kearifan lokal Jawa yang diturunkan oleh nenek moyang di antaranya adalah sebagai berikut. 
a. Tepa slira (toleransi) adalah suatu perilaku atau sikap manusia yang tidak menyimpang dari aturan, di mana seseorang harus menghormati atau menghargai setiap tindakan yang dilakukan oleh orang lain (Ihsan dalam Digdoyo, 2018). Tepa slira mengajarkan bahwa seseorang supaya mampu melihat dan merasakan dari sudut pandang orang lain. Dengan kata lain tepa slira ialah seseorang dituntut untuk memiliki sifat tenggang rasa, peduli terhadap sesama, dan harus berfikir terlebih dahulu sebelum bertindak agar tidak menyakiti orang lain.

b. Mawas diri adalah memeriksa hati nurani yang ada dalam diri kita sudah sesuai dengan norma-norma dan tata nilai atau belum (Budiyono \& Yoga Feriandi, 2017). Masyarakat Jawa yang menjalankan perilaku mawas diri merupakan usaha sadar dari diri sendiri untuk menjadi pribadi yang baik dalam bertindak dan dapat menjadi suritauladan bagi orang lain.

c. Budi luhur (budi pekerti) adalah sebuah pendidikan yang dimulai dari anak kecil untuk menimbang baik dan buruknya dalam suatu tindakan. Pendidikan dapat dilaksanakan di dalam keluarga maupun di sekolah.

d. Rukun (cinta damai) adalah sikap, perkataan dan perbuatan yang menyebabkan orang lain merasa senang dan aman atas kehadiran dirinya (Wibowo dalam Syaefudin and Santoso, 2018). Nilai ini sudah ada sejak dahulu dan berakar dari kebiasaan orang Jawa yang memiliki kebiasaan untuk hidup rukun dan saling menghormati sesama manusia. Sikap ini sangat penting ditanamkan pada diri seseorang untuk membentuk kepribadian yang baik.

e. Rumangsa melu handarbeni (peduli sosial) adalah suatu tindakan untuk peduli terhadap lingkungan sosial dan sekitarnya yang membuat seseorang tergerak untuk saling membantu kepada orang lain yang membutuhkan (Fauzi et al., 2017). Peduli sosial merupakan sikap dan tindakan yang selalu ingin memberi bantuan kepada orang yang membutuhkan. Hal ini yang harus ditanamkan oleh seluruh masyarakat untuk saling membantu satu sama lain.

f. Memayu hayuning bawana (peduli lingkungan) dapat diartikan sebagai sikap dan Tindakan yang berupaya untuk mencegah kerusakan lingkungan alam dan mengembangkan upaya-upaya untuk memperbaiki kerusakan alam yang sudah terjadi (Iswari, 2017). Sebagai manusia wajib melindungi lingkungan alam, karena alam sebagai mata pencaharian.

g. Aja dumeh (menghargai, jujur, dan rendah hati) dapat diartikan sebagai suatu sumber nilai-nilai moral kewarganegaraan yang berlaku universal karena ungkapan ini mengandung ajaran untuk menjadi manusia yang selalu bertata krama, amanah, dan dapat dipercaya (Feriandi, 2017). Nilai ini yang menjadi dasar dan modal untuk menjadi warga negara yang baik, dengan berlandaskan kejujuran dan rendah hati, maka karakter seseorang dapat terbentuk dengan baik.

Nilai-nilai kearifan lokal Jawa memiliki kelebihan terutama bagi masyarakat Jawa. Beberapa kearifan lokal yang dimiliki suku Jawa belum tentu dimiliki oleh suku lain di Indonesia. Ini berarti, nilai-nilai kearifan lokal yang ada harus tetap dijaga dan dilestarikan untuk menjadi acuan kehidupan baik secara pribadi maupun dalam bermasyarakat luas. Manfaat nilai-nilai kearifan lokal salah satunya adalah memberikan kemudahan dalam berperilaku sebagai warga negara yang baik dalam mewujudkan pengamalan nilai-nilai Pancasila secara nyata.

\section{Pengamalan Nilai-nilai Pancasila}

Indonesia sebagai negara kesatuan yang memiliki ideologi Pancasila yang dijadikan pedoman atau pandangan hidup untuk menjadi warga negara yang baik serta menjadi pemersatu dari kemajemukan bangsa Indonesia. Pancasila sebagai nilai filsafat yang mendasar dijadikan aturan-aturan dan norma-norma yang berlaku di Indonesia sehingga semua aturan yang berlaku bersumber pada Pancasila. Nilai yang terkandung pada Pancasila merupakan sebuah komitmen kebangsaan dan identitas suatu bangsa untuk membangun karakter suatu bangsa, menjadi salah satu dasar 
untuk menyatukan kebhinekaan yang ada. Pancasila lahir dan dicetuskan oleh para pendiri bangsa supaya menjadi dasar atau pondasi yang kuat dalam menjalankan kehidupan berbangsa dan bernegara.

Masyarakat Indonesia dalam kehidupan dan perilaku sehari-hari menerapkan Pancasila sebagai pandangan hidup yang mengandung pengertian bahwa Pancasila merupakan pedoman untuk mengatur sikap dan tingkah laku seseorang. Masyarakat Indonesia harus mengamalkan nilai-nilai Pancasila supaya dapat menjadi warga negara yang baik dan menjalankan hak dan kewajiban sebagai warga negara Indonesia. Bentuk pengamalan nilai-nilai Pancasila dapat dilihat dari perilaku seharihari yang tercermin dari butir sila Pancasila. Pengamalan butir-butir Pancasila (Pertahanan, n.d., 2014), dapat dijabarkan menjadi sebagai berikut.

a. Pada sila pertama "Ketuhanan Yang Maha Esa". Indonesia menyatakan kepercayaan dan ketaqwaanya terhadapTuhan Yang Maha Esa, masyarakat Indonesia percaya dan taqwa terhadapTuhan Yang Maha Esa sesuai dengan keyakinannya masing-masing, mempunyai sikap saling menghormati dan bekerjasama antara pemeluk agama satu dengan lainnya, menjaga dan membina kerukunan hidup, mempunyai sikap saling menghormati kebebasan dalam menjalankan ibadah sesuai dengan keyakinan masing-masing.

b. Pada sila kedua "Kemanusiaan Yang Adil dan Beradab". Mengakui dan memperlakukan manusia sebagai makhluk Tuhan Yang Maha Esa, mengakui adanya persamaan derajad, hak dan kewajiban asasi setiap manusia tanpa membedakan latar belakang seseorang, (seperti: suku, agama, ras, keturunan, jenis kelamin dan sebagainya), mempunyai sikap saling mencintai antar sesama manusia, memiliki sikap saling tenggang rasa, mengembangkan sikap tidak semena-mena kepada orang lain, menjunjung dan mengutamakan nilai kemanusiaan, membela kebenaran dan keadilan, serta memiliki rasa hormat dan bekerjasama dengan bangsa lain.

c. Pada sila ketiga "Persatuan Indonesia". Mampu menempatkan persatuan dan kesatuan di atas kepentingan bersama, harus sanggup dan rela berkorban untuk kepentingan bangsa dan negara, memiliki rasa cinta terhadap tanah air, mempunyai rasa bangga menjadi masyarakat Indonesia, tetap menjaga ketertiban dunia yang berdasar kemerdekaan perdamaian dan keadilan sosial, menjaga persatuan Indonesia atas dasar Bhineka Tunggal lka.

d. Pada sila keempat "Kerakyatan yang dipimpin oleh Hikmat Kebijaksanaan dalam Permusyawaratan Perwakilan". Setiap warga negara memiliki kedudukan hak dan kewajiban yang sama, mengutamakan musyawarah dalam mengambil keputusan untuk kepentingan bersama, melakukan musyawarah untuk mencapai mufakat, menghormati dan menjunjung tinggi dari hasil musyawarah dengan i'tikad baik dan rasa tanggung Jawab, musyawarah dilakukan dengan akal sehat dan sesuai hati nurani, keputusan yang diambil dapat dipertangggung Jawabkan secara moral kepada Tuhan Yang Maha Esa serta menjunjung tinggi harkat dan martabat manusia dalam kebenaran dan keadilan demi kepentingan bersama, memberikan kepercayaan kepada wakil yang dipercaya untuk melaksanakan permusyawaratan.

e. Pada sila kelima "Keadilan Sosial Bagi Seluruh Rakyat Indonesia". Memiliki perbuatan yang luhur dan mencerminkan kekeluargaan dan gotong royong, mempunyai sikap adil kepada sesama, menjada dan melaksanakan hak dan kewajiban, memberikan pertolongan kepada orang lain, menghargai karya orang lain, melaksanakan kegiatan untuk mewujudkan kemajuan yang merata dan keadilan sosial.

Masyarakat Indonesia dalam kehidupan dan berperilaku sehari-hari harus mencerminkan sila-sila Pancasila. Nilai-nilai dalam Pancasila tidak mengalami perubahan tetapi dengan seiring berjalannya waktu maka dalam implementasinya sangat dimungkinkan terjadi penyesuaian. Karena itu diperlukan strategi, yakni 
semacam penggalian nilai-nilai kearifan lokal bagi penguatan pengamalan nilai-nilai Pancasila di tengah masyarakat.

\section{Implementasi Kearifan Lokal Jawa dalam Pengamalan Pancasila}

Sebagai warga negara Indonesia yang berpedoman pada ideologi Pancasila, pada praktek kehidupan sehari-hari harus tercermin pada nilai-nilai yang terkandung dalam Pancasila, masyarakat Jawa memiliki kearifan lokal dapat dijadikan pedoman dalam berperilaku untuk melaksanaka hak dan kewajiban sebagai warga negara sebagai upaya untuk mengamalkan nilai-nilai Pancasila.

Berdasarkan hasil penelitian Wartoyo (2017), dijelaskan bahwa realita dalam kehidupan bersama dengan perbedaan suku, ras, agama, budaya tetap bersatu saling melengkapi yang dibungkus dengan kebhinekaan hidup gotong royong sesuai dengan konsep budaya Jawa yang diyakini kebenarannya dalam mengimplementasikan nilainilai Pancasila. Selanjutnya hasil penelitian Anang \& Zuhroh (2019), menunjukan bahwa toleransi antar sesama meliputi manusia dan makhluk Tuhan lainnya ditunjukkan dengan sikap saling menghormati, menghargai, dan saling tolong menolong antara pemeluk agama satu dengan lainnya, dengan adanya sikap toleransi yang bertujuan untuk mengamalkan Pancasila dan menjaga keutuhan NKRI. Selanjutnya hasil penelitian Mariatun \& Indriani (2018), menunjukkan hasil penelitian dari lima Sekolah Dasar yakni SDN Banyuajuh 2, SDN Banyuajuh 3, SDN Banyuajuh 6, SDN Kamal 1, SDN Gili Anyar, menunjukan bahwa presentase perilaku yang menunjukan karakter dalam penguatan nilai-nilai Pancasila ialah aspek peduli sosial $80 \%$, kejujuran $79 \%$, menghargai prestasi $76 \%$, religius dan toleransi $75 \%$ dari hasil penelaahan bahwa beberapa karakter yang mengandung nilai Pancasila sebagai pandangan hidup merupakan tameng utama untuk menghadapi tantangan dan ancaman bangsa Indonesia.

Kearifan lokal Jawa menjadi salah satu indikasi untuk mengamalkan Pancasila, dengan melaksanakan dan meyakini kearifan lokal yang ada. Dengan demikian berdasarkan hasil penelitian dan kajian yang ditemukan menunjukkan bahwa implementasi nilai kearifan lokal Jawa dapat memberikan penguatan pada pengamalan nilai-nilai Pancasila.

\section{SIMPULAN}

Indonesia merupakan negara multikultural yang memiliki ideologi Pancasila sebagai pandangan hidup yang harus dijalankan oleh seluruh elemen masyarakat. Masyarakat Indonesia saat ini belum sepenuhnya mengamalkan nilai-nilai Pancasila, hal ini ditunjukkan dengan sikap dan perilaku masyarakat yang masih bertentangan dengan nilai-nilai Pancasila. Masyarakat Jawa dalam berperilaku sehari-hari mendasarkan diri pada kearifan lokal Jawa, oleh karena itu masyarakat Jawa yang melaksanakan kearifan lokal yang ada, maka secara tidak langsung telah mengamalkan nilai-nilai Pancasila. Kearifan lokal Jawa sebagai sarana untuk memperbaiki diri dengan alam maupun dengan pencipta-Nya. 


\section{DAFTAR PUSTAKA}

Anang, \& Zuhroh, K. (2019). Nilai-Nilai Toleransi Antar Sesama Dan Antar Umat Beragama (Studi Pandangan KH. Sholeh Bahruddin). Multicultural Islamic Education, 3(1), 41-55. https://doi.org/10.35891/ims.v3i1.1730

Budiyono \& Yoga Feriandi, A. (2017). Menggali Nilai Nilai Kearifan Lokal Budaya. Prosiding Seminar Nasional Bimbingan Dan Konseling, 1(1), 92-103. http://regional.kompas.com/read/201

Digdoyo, E. (2018). Kajian Isu Toleransi Beragama, Budaya, Dan Tanggung Jawab Sosial Media. Jurnal Pancasila Dan Kewarganegaraan, 3(1), 42-59. https://doi.org/10.24269/jpk.v3.n1.2018.pp42-59

Fauzi, A. R., Atok, R. Al, \& Zainuddin. (2017). Penguatan Karakter Rasa Ingin Tahu Dan Peduli Sosial Melalui Discovery Learning. Jurnal Teori Dan Praksis Pembelajaran IPS, 2(2), 27-36.

Feriandi, Y. A. (2017). Revitalisasi Moral Kewarganegaraan Dalam Ungkapan Jawa Sebagai Sumber Pembentukan Civic Culture Dan Politic Culture. Jurnal Civics: Media Kajian Kewarganegaraan, 14(2), 176-182. Retrieved From Https://Journal.Uny.Ac.Id/Index.Php/Civics/Article/Download/15323/Pdf

Iswari, D. R (2017). Evaluasi Penerapan Program Adiwiyata Untuk Membentuk Perilaku Peduli Lingkungan. Jurnal Ilmu Lingkungan, 3637. Https://Ejournal. Undip.Ac.Id/Index.Php/IImulingkungan/Article/View/13012

Kasari, O. (2020). Tumbuh kembang: Kajian Teori dan Pembelajaran PAUD Jurnal PG-PAUD FKIP Universitas Sriwijaya. Tumbuh Kembang: Kajian Teori Dan Pembelajaran PAUD Jurnal PG PAUD FKIP Universitas Sriwijaya, 7(November), 97-105. https://doi.org/10.36706/jtk.

Mariatun, I. L., \& Indriani, D. E. (2018). Penguatan Pendidikan Karakter Berbasis Pancasila melalui Kurikulum K13 di Sekolah Dasar. 9924, 153-160.

Mirzaqon, A., \& Purwoko, B. (2018). Studi Kepustakaan Mengenai Landasan Teori Dan Praktik Konseling Expressive Writing Library. Jurnal BK UNESA, 1, 1-8.

Nakrowi, Z. S., \& Pujiyanti, A. (2019). Strategi Kesantunan Berbahasa Suku Jawa Dalam Interaksi Antarsuku Di Halmahera Utara. RETORIKA: Jurnal Bahasa, Sastra, Dan Pengajarannya, 12(1), 105. https://doi.org/10.26858/retorika.v12i1.6909

Nugraha, D. (2020). Urgensi Pendidikan Multikultural Di Ndonesia. Jurnal Pendidikan PKN (Pancasila Dan Kewarganegaraan), 1(2), 140. https://doi.org/10.26418/jppkn.v1i2.40809

Octavia, S. S., \& Nurlatifah, L. (2020). Implementasi Nilai-Nilai Kearifan Budaya Lokal Jawa Dan Sunda Sebagai Bahan Pembelajaran. 487-497.

Pertahanan, K. (n.d.).45-butir-pedoman-penghayatan-dan-pengamalan-Pancasila@ www.kemhan.go.id. https://www.kemhan.go.id/renhan/2014/11/20/45-butirpedoman-penghayatan-dan-pengamalan-Pancasila.html

Prasasti, S. (2020). Konseling Indigenous: Menggali Nilai-Nilai Kearifan Lokal Tradisi Sedekah Bumi dalam Budaya Jawa. Journal of Chemical Information and Modeling, 14(2), 110-123. https://doi.org/10.30957/Cendekia.v14i2.626.satu

Rumilah, S., Nafisah, K. S., Arizamroni, M., Hikam, S. A., \& Damayanti, S. A. (2021). Kearifan Lokal Masyarakat Jawa dalam Menghadapi Pandemi. SULUK: Jurnal Bahasa, Sastra, Dan Budaya, 2Digdoyo,(2), 119-129. https://doi.org/10.15642/suluk.2020.2.2.119-129

Syaefudin, \& Santoso, S. (2018). Tipologi Kepemimpinan Kepala Sekolah dalam Pembentukan Karakter Cinta Damai Siswa SMP Piri 1 Yogyakarta. MANAGERIA: Jurnal Manajemen Pendidikan Islam, 3(1), 47-67. https://doi.org/10.14421/manageria.2018.31-03

Wartoyo, F. X. (2017). Kearifan Lokal Budaya Jawa Dalam Perspektif Pancasila. WASKITA: Jurnal Pendidikan Nilai Dan Pembangunan Karakter, 2(2), 83-88. 
SHEs: Conference Series 4 (4) (2021) $186-193$

https://doi.org/10.21776/ub.waskita:jurnalpendidikannilaidanpembangunankarak ter.2018.002.02.8

Yeni, A., \& Hartati, S. (2020). Studi Literatur: Stimulasi Kemampuan Anak Mengenal Huruf Melalui Permainan Menguraikan Kata Di Taman Kanak-Kanak Alwidjar Padang. Jurnal Pendidikan Tambusai, 4, 608-616. 